\title{
Análise da disponibilidade de alimentos volumosos em propriedades leiteiras da agricultura familiar no município de Ponte Nova/MG: um estudo multicasos
}

\author{
Analysis of the availability of roughages on dairy farms of familiar \\ farming in the municipality of Ponte Nova/MG: a multicase study
}

Graciela Pires Lazarini[ ${ }^{[a]}$, Marcos Aurélio Lopes ${ }^{[b]^{*}}$, Milton Ghedini Cardoso[c]

\footnotetext{
[a] Empresa de Assistência Técnica e Extensão Rural do Estado de Minas Gerais, Ponte Nova, MG, Brasil

${ }^{[b]}$ Departamento de Medicina Veterinária, Universidade Federal de Lavras (UFLA), Lavras, MG, Brasil

${ }^{[c]}$ Médico veterinário, Alfenas, MG, Brasil
}

*Autor correspondente

E-mail: malopes@dmv.ufla.br

\section{Resumo}

Objetivou-se analisar a disponibilidade de alimentos volumosos em propriedades leiteiras em regime de economia familiar, visando orientar produtores quanto às melhores alternativas de sustentabilidade financeira e ambiental no município de Ponte Nova, Zona da Mata Mineira. Durante o mês de abril de 2016, cinco pecuaristas foram entrevistados utilizando-se um formulário semiestruturado com 47 questões de múltipla escolha e 50 abertas, visando conhecer a quantidade de animais existentes, as fontes de alimentos e o período de arraçoamento dos animais. Para efetuar a mensuração das áreas de alimentação foi utilizado o Google Earth Pro ${ }^{\circledR}$. As pastagens encontradas nas propriedades são à base de Brachiaria brizantha, Brachiaria decumbens e capins nativos, manejadas em lotação contínua ou em piquetes rotacionados. Os principais alimentos volumosos cultivados encontrados foram capineiras de capim elefante (Pennisetum purpureum), cana-de-açúcar (Saccharum officinarum) e silagem de milho (Zea mays). Conclui-se que 80\% das propriedades não tem alimentação suficiente para todos os animais no decorrer de um ano.

Palavras-chave: Agricultura Familiar. Alimentação. Bovinocultura de Leite. Pastagens. Volumoso.

\section{Abstract}

It was intended to analyze the availability of roughages on dairy farms under familiar economics, aiming to guide the farmers as to the improvements of both financial and environmental sustainability alternatives regime in the municipality of Ponte Nova, Zona da Mata Mineira (Minas Gerais' Zona da Mata region). During 
April 2016 five farmers were interviewed by utilizing a semi-structured formulary with 47 multiple-choice questions and 50 open questions, aiming to know the amount of animals, sources of feed and period of feeding of the animals. To accomplish the measurement of the feeding areas, Google Earth Pro ${ }^{\circledR}$ was utilized. The pastures found on the farms are based upon Brachiaria brizantha, Brachiaria decumbens and native grasses, managed either in continuous stocking or in rotated fenced fields. The main cultivated roughages found were forage banks of elephant grass (Pennisetum purpureum), sugarcane (Saccharum officinarum) and corn silage (Zea mays). It follows that $80 \%$ of the farms do not have enough feeding for all the animals over one year time.

Keywords: Familiar Farming. Feeding. Dairy Cattle Production. Pastures. Roughage.

\section{Introdução}

A pecuária leiteira é uma das atividades mais importantes do país e desempenha papel relevante na produção de alimentos e na geração de emprego e renda. 0 estado de Minas Gerais é o maior produtor nacional, participando com 26\% da produção brasileira em 2015 (IBGE, 2016). A agricultura familiar contribui com cerca de $45 \%$ do valor bruto da produção e desempenha um papel de grande importância social, com participação de $79 \%$ dos estabelecimentos rurais do estado e dando ocupação para $62 \%$ da mão de obra no meio rural (França et al., 2009).

A maior parte do leite produzido no Brasil é proveniente de pequenas e médias propriedades e sua produção está baseada, principalmente, no uso de pastagens. Concentra sua melhor produtividade nos períodos de chuvas, reduzindo significativamente a produção no inverno (Nussio et al., 1998) e em época de secas em boa parte do território nacional, inclusive Minas Gerais, o que leva a uma baixa oferta de forragens. A baixa produção de forragens durante $o$ período seco do ano tem sido apontada como um dos principais fatores que contribui para a produtividade reduzida dos rebanhos baseados em pastagens. A limitação na capacidade de suporte de pastagens tem contribuído para a queda acentuada nos índices de produção. Assim, a estacionalidade de produção de forragens não conservadas dificulta a rentabilidade da atividade pecuária, pois o potencial de produção não pode ser alcançado, uma vez que o estoque de animais nas pastagens é ajustado em função da produção mínima de “inverno" (Daniel et al., 2011).
O município de Ponte Nova, localizado na Zona da Mata Mineira, tem temperaturas altas de setembro a abril; de maio a agosto o tempo fica mais fresco. As temperaturas máximas chegam a $35^{\circ} \mathrm{C}$ e as mínimas, a $10^{\circ} \mathrm{C}$. Os solos, no geral, são pobres, com baixos teores de fósforo e alta acidez. 0 relevo é montanhoso. As pastagens, em sua maioria absoluta, encontram-se altamente degradadas em razão do seu uso intensivo, do super pastoreio e da baixa adoção de técnicas conservacionistas, como a fenação e ensilagem. Outro fator peculiar é a presença de espécies invasoras, que são altamente adaptadas às características da região e se desenvolvem de forma agressiva, dominando rapidamente a pastagem (Viana et al., 2010).

Muitos pecuaristas não se preocupam com o fator de produção "terra" e com o planejamento e otimização do seu uso. Lopes et al. (2004), ao estimarem índices técnicos gerenciais em 16 sistemas de produção de leite na região de Lavras/MG, observaram que a taxa de lotação foi de 0,8 vacas em lactação/ha; mesmo assim, as pastagens encontravam-se em péssimas condições. 0 dimensionamento adequado das categorias animais é de grande importância para aumentar a lucratividade das fazendas. Campos e Ferreira (2006) afirmaram que a composição de rebanho é uma ferramenta importante e pouco utilizada no planejamento da propriedade leiteira. Isso fica evidente em rebanhos que apresentam reduzida quantidade de animais em lactação em relação às outras categorias animais, havendo um reflexo direto na rentabilidade da propriedade, já que as vacas em lactação são as responsáveis pela maior 
parte da receita da propriedade (Lopes et al., 2011; Santos e Lopes, 2012; Lopes e Santos, 2013; Santos e Lopes, 2014; Lopes et al., 2015).

Nesse contexto, objetivou-se analisar a disponibilidade de alimentos volumosos em cinco propriedades leiteiras, em regime de economia familiar, no município de Ponte Nova, Zona da Mata Mineira.

\section{Material e métodos}

O estudo foi realizado em Ponte Nova, Zona da Mata de Minas Gerais, utilizando um formulário semiestruturado com 47 questões de múltipla escolha e 50 abertas. 0 questionário foi aplicado a cinco pecuaristas em regime de agricultura familiar, durante o mês de abril de 2016, visando conhecer a quantidade de animais existentes, as fontes de alimentos e período de fornecimento de ração balanceada aos animais. As propriedades analisadas foram escolhidas utilizando-se amostragem não probabilística por julgamento, levando-se em consideração os seguintes critérios: disponibilidade e qualidade de dados, consentimento e interesse do pecuarista na realização da pesquisa e facilidade de acesso por parte do pesquisador às fontes de evidências (Lopes et al., 2015).

A elaboração do formulário baseou-se naquele elaborado e validado por Lopes et al. (2016), excluindo-se várias questões que não se relacionavam ao objetivo desta pesquisa. 0 primeiro grupo de questões foi elaborado com o intuito de identificar o produtor e conhecer a propriedade. 0 segundo, com a necessidade de conhecer o rebanho em quantidade e idade. E o terceiro buscou caracterizar o sistema de produção de leite em itens específicos para conhecimento das áreas e da produtividade das pastagens, capineiras, milho (Zea mays) e cana-de-açúcar (Saccharum officinarum), bem como a quantidade de animais, as práticas agrícolas e o manejo alimentar.

Para aferir a área cultivada, realizou-se mensuração da área através de marcação de polígonos por meio do Google Earth Pro $^{\circledR}$. A produção de volumoso de cada propriedade foi estimada com base nas produtividades médias da região. Os valores utilizados de matéria natural
(MN), em toneladas por hectare $\backslash$ ano, foram: capim meloso, 10; braquiária em pastejo contínuo, 20; braquiária em piquetes, 30; capineira com capim elefante, 40; cana-de-açúcar, 100; silagem de milho, 40. Considerou-se que as pastagens, capineiras, cana-de-açúcar e a silagem de milho possuíam 25 , 25,30 e 35\% de matéria seca (MS), respectivamente.

Nos cálculos, considerou-se que uma vaca (seca ou em lactação) pesava $450 \mathrm{~kg}$; uma fêmea ou macho menor que 12 meses, peso médio de $90 \mathrm{~kg}$ (peso do animal recém-nascido somado ao animal com 12 meses, dividido por 2); fêmeas com 12 a 24 meses, peso de $200 \mathrm{~kg}$ (peso do animal com 12 meses somado ao animal com 24 meses, dividido por 2); e fêmeas com 24 meses a 36 meses, $350 \mathrm{~kg}$ (peso do animal com 24 meses somado ao animal com 36 meses, dividido por 2). Para estimar o consumo de MS por animal, considerou-se percentuais diferentes para cada categoria animal (Tabela 1).

Tabela 1 - Peso vivo (PV) e consumo de matéria seca (MS) por categoria animal das cinco propriedades de agricultura familiar estudadas no município de Ponte Nova/MG (período de abril a junho de 2016)

\begin{tabular}{lcc}
\hline Categoria animal & $\begin{array}{c}\text { Peso vivo } \\
(\mathrm{kg})\end{array}$ & $\begin{array}{c}\text { Consumo de MS em } \\
\text { relação ao PV } \\
(\%)\end{array}$ \\
\hline Vacas em lactação & 450 & 3,0 \\
Vacas secas & 450 & 2,0 \\
Bezerras de 0 a 12 meses & 90 & 2,5 \\
Novilhas de 13 a 24 meses & 200 & 2,5 \\
Novilhas de 25 a 36 meses & 350 & 2,5 \\
Touros & 540 & 1,5 \\
Boi de carro & 600 & 1,5 \\
Cavalos & 450 & 2,0 \\
Mulas & 350 & 2,0 \\
\hline
\end{tabular}

O sistema de criação foi em regime de pastejo em todas as propriedades. Quando arraçoados, o alimento é fornecido no cocho à vontade nas propriedades A e B; nas propriedades C, D e E é com restrição. Todas as propriedades fornecem sal mineral. As produções diárias de leite foram de 120 , 50, 4010 e 60 litros para as propriedades A, B, C, D e E, respectivamente. 
Os dados foram comparados por meio de análises descritivas, utilizando-se o aplicativo MS Excel $^{\circledR}$, e agrupados em tabelas, objetivando realizar melhores comparações, discussões e apresentação dos resultados (Lopes et al., 2004).

\section{Resultados e discussão}

Um resumo do perfil dos cinco produtores estudados no município de Ponte Nova (MG), entrevistados durante o mês de abril de 2016, pode ser observado na Tabela 2 . 0 perfil dos cinco produtores estudados assemelha-se em alguns pontos ao observado por Zoccal et al. (2005) em produtores da Zona da Mata Mineira: 70\% residem na propriedade rural, 36\% contratam mão de obra permanente, $96 \%$ fazem ordenha manual. Porém, outros pontos mostram uma evolução do nível de estudo e capacitação em relação ao estudo de 2005: somente $22 \%$ possuíam ensino fundamental completo e $40 \%$ receberam algum tipo de treinamento.

Tabela 2 - Perfil dos cinco produtores de agricultura familiar estudados no município de Ponte Nova/MG (período de abril a junho de 2016)

\begin{tabular}{|c|c|}
\hline Item & Ocorrência (\%) \\
\hline \multirow[t]{2}{*}{ Local onde moram } & Propriedade (80) \\
\hline & Cidade (20) \\
\hline \multirow[t]{2}{*}{ Escolaridade } & Fundamental incompleto (40) \\
\hline & Fundamental completo (60) \\
\hline Forma de aquisição da propriedade & Compra (100) \\
\hline \multirow[t]{3}{*}{ Tipo de mão de obra } & Exclusivamente familiar (40) \\
\hline & Familiar + temporária $(40)$ \\
\hline & Familiar + permanente ${ }^{2}(20)$ \\
\hline \multirow[t]{2}{*}{ Tipo de ordenha } & Manual (80) \\
\hline & Mecânica (20) \\
\hline \multirow{2}{*}{$\begin{array}{l}\text { Participação em projetos de } \\
\text { incentivo a pecuária }\end{array}$} & $\operatorname{Sim}(60)$ \\
\hline & Não (40) \\
\hline \multirow[t]{2}{*}{ Busca por capacitação ${ }^{3}$} & $\operatorname{Sim}(80)$ \\
\hline & Não (20) \\
\hline
\end{tabular}

Nota: ${ }^{1}$ Contração de mão de obra esporádica para trabalhos eventuais; ${ }^{2}$ Contratada durante todo 0 ano; ${ }^{3}$ Buscam algum tipo de capacitação pelo menos uma vez ao ano (Programa municipal de apoio à bovinocultura).
0 gerenciamento adequado das propriedades rurais é fundamental para o sucesso da atividade. Ao residir na propriedade, o produtor tende a acompanhar melhor todos os acontecimentos da atividade, além de diminuir os custos de moradia e deslocamento. No caso de pequenas propriedades, o residir na propriedade reduz ou até mesmo evita as despesas com funcionários, com consequente aumento na rentabilidade, pois essa, depois da alimentação, constitui o item de maior representatividade no custo operacional efetivo na atividade leiteira (Lopes et al., 2012; Santos e Lopes, 2014; Ferrazza et al., 2015; Lopes et al., 2015; Teixeira Júnior et al., 2016). 0 aumento do nível de escolaridade e da busca por capacitação também contribuem para melhorar a capacidade dos produtores de gerenciar as propriedades.

No que diz respeito à alimentação, uma propriedade (20\%) faz uso de piquete rotacionado (Brachiaria decumbens) com dias fixos, sendo o plantio realizado pelo sistema direto. Nas demais, as pastagens foram plantadas pelo sistema convencional; apenas uma tem pastagem nativa. No estudo de Zoccal et al. (2005), as principais fontes de alimentação dos rebanhos foram as pastagens nativas (64\%) e as cultivadas de braquiária (86\%). Segundo Magalhães et al. (2007), a utilização de pastagem tropical para produção de leite no Brasil se dá principalmente devido aos baixos custos de produção; por outro lado, fatores como a adubação das pastagens e a melhoria do manejo viabilizam a utilização do sistema de lotação rotacionada, permitindo uma maior taxa de lotação de animais em pastagens e a eficiência de uso das mesmas.

Os produtores também fornecem suplementação volumosa no cocho, sendo que $60 \%$ o fazem apenas durante o período seco. Os volumosos utilizados são a silagem de milho (40\%), a cana-de-açúcar (40\%) e o capim elefante (Pennisetum purpureum) (20\%). No estudo de Zoccal et al. (2005), as suplementações volumosas com capineira e com cana-de-açúcar foram encontradas em $22 \%$ e $14 \%$ dos produtores, respectivamente.

O uso da silagem de milho na alimentação devese principalmente ao seu elevado valor nutritivo (Cruz e Pereira Filho, 2001), onde o percentual de NDT por quilograma de MS propicia maiores produtividades animais, porém a produtividade 
por hectare é muito variável e possui alto custo de produção (França e Coelho, 2001). Como alternativa ao milho, tem-se o capim-elefante, cujo rendimento por área é elevado, reduzindo os custos de produção de matéria seca por hectare. Um dos principais obstáculos par o uso desse volumoso é o elevado teor de umidade da planta e o reduzido teor de carboidratos solúveis, o que ocasiona menores produtividades (Ferreira, 2001). A cana-de-açúcar surge como uma opção vantajosa por se tratar de um alimento rico em carboidratos solúveis, pela elevada produtividade e, principalmente, por estar disponível no período da seca (Magalhães et al., 2004). Entretanto, existem limitações quanto ao consumo dessa forrageira por bovinos, com médio a alto potencial de produção, devido à baixa digestibilidade da sua fibra (Magalhães et al., 2004).

No estudo de Oliveira et al. (2011), onde foi avaliado o uso de silagem de milho, silagem de capim-elefante e cana-de-açúcar em dietas de vacas de leite na época da seca, observou-se que as dietas à base de silagem de milho proporcionaram maiores consumos de matéria seca, associado ao maior consumo de nutrientes. A dieta com cana-de-açúcar, mesmo apresentando produções de leite inferiores em comparação à dieta com silagem de milho, foi a que proporcionou melhor retorno econômico, quando comparada às demais em relação aos custos da alimentação, consumo de matéria seca e preço do leite, para vacas leiteiras mestiças, de produção média diária de $12 \mathrm{~kg}$ de leite.

A suplementação concentrada é feita por $80 \%$ dos produtores. 0 consumo diário de concentrado por vaca de duas propriedades $(40 \%)$ é de $1 \mathrm{~kg}$, de uma (20\%) é de $3 \mathrm{~kg}$ e da outra (20\%) é proporcional à quantidade de leite produzida (1 $\mathrm{kg}$ de concentrado para cada 3 litros de leite produzidos); em uma (20\%) propriedade, as vacas não consomem concentrado. Segundo Moreira (1984), o fornecimento de concentrado em quantidade fixa pode subalimentar as vacas mais produtivas, com prejuízos para a produção de leite, e superalimentar as menos produtivas, podendo elevar os custos dos sistemas de produção.

Zoccal et al. (2005) observaram que $84 \%$ dos produtores usavam suplementação concentrada (farelo de trigo e ou milho moído) e apenas $2 \%$ utilizavam suplementação mineral, dos quais
$49 \%$ suplementavam durante todo o ano e $35 \%$ só no período seco. A suplementação concentrada de forma não balanceada (apenas alimentos energéticos) pode explicar a baixa produção $(4,65$ litros/vaca/dia) observada no estudo de Zoccal et al. (2005), diferente do observado neste estudo, onde a suplementação era feita com uso de ração balanceada (ração comercial) e a média de produção observada é de 7,06 litros.

Os nutrientes suplementares corrigem as deficiências de nutrientes no rúmen e fornecem ao animal nutrientes que não podem ser obtidos na forragem (Mc-Collum, 2005). Segundo Silva et al. (2010), o conhecimento das limitações nutricionais das forragens e a adoção de estratégias de alimentação nos períodos do ano em que suas deficiências são mais evidentes são pilares para a manutenção e produtividade dos sistemas.

Em alguns sistemas de produção a pasto faz-se necessário o uso de complementos alimentares para que seja mantido o desempenho animal, pensando em produção de leite e/ou ganho de peso em níveis aceitáveis (Reis e Antunes, 1999).

0 produtor A possui uma área total de 10,7 ha, sendo 2,43 ha destinados ao cultivo de café, mandioca e infraestrutura, e o restante à produção de leite, assim distribuídos: áreas de pastagem somam 6,27 ha, sendo 3,33 ha divididos em piquetes com permanência das vacas em lactação por três dias; os outros 1,56 ha, com cultivo de linhas de eucaliptos de 10 em $10 \mathrm{~m}$ e entre plantas com $3 \mathrm{~m}$, ambas de Brachiaria decumbens e 1,38 ha de pastagem nativa, totalizando 43,20 t de MS. A área de cana-de-açúcar ocupa 0,59 ha, com produção de 59 t; a de milho é de 3 ha, sendo cultivados fora da propriedade, em área emprestada (sem custo), produzindo $120 \mathrm{t}$ de MN e $42 \mathrm{t}$ de MS. 0 cultivo de capim elefante ocupa uma área de 0,47 ha, produzindo 30,04 t de $\mathrm{MN}$ e 7,6 de MS.

0 produtor B possui uma área total de 6,12 ha, sendo 2,09 ha destinados a pomar e infraestrutura e o restante à produção de leite, assim distribuídos: a área de pastagem é de 2,70 ha de Brachiaria decumbens, sendo 2,00 ha arrendados, ao custo de $\mathrm{R} \$ 30,00 /$ animal, com produção de MS de 16,20 t. A produção de cana-de-açúcar ocupa um espaço de 0,10 ha, com produção de $10 \mathrm{t}$ de $\mathrm{MN}$ e $3 \mathrm{t}$ de MS. 0 cultivo de capim elefante ocupa uma área 0,23 ha, 
produzindo 9,20 t de MN e 2,3 de MS. A produção de milho ocupa 1 ha, com $40 \mathrm{t}$ de MN e $14 \mathrm{t}$ de MS.

0 produtor $C$ possui uma área total de 17,70 ha, sendo 11,24 ha destinados a eucalipto e infraestrutura e o restante à produção de leite, assim distribuídos: a área de pastagem nativa é de 6,01 ha, com produção da MS de 18,03 t; aluga 2 ha de Brachiaria brizantha, com custo de R\$200,00 por mês, com MS de 12 t. A produção de cana-deaçúcar ocupa um espaço de 0,25 hectares, com produção de $25 \mathrm{t}$ de MN e 7,5 t de MS. 0 cultivo de capim elefante ocupa uma área 0,20 ha, produzindo 9,20 t de MN e 2,30 de MS.

0 produtor $\mathrm{D}$ possui uma área total de $3,88 \mathrm{ha}$, sendo 0,17 ha destinados a pomar e infraestrutura e o restante à produção de leite, assim distribuídos: a área de pastagem nativa é de 3,01 ha, com produção de MS de 9,02 t, de pasto alugado com custo de R $\$$ 100,00/mês; tem 1 ha de Brachiaria decumbens e 0,6 ha de sua propriedade com a mesma espécie, totalizando em pastagem 9,06 t de MS. A produção de cana-de-açúcar ocupa um espaço de 0,10 ha com produção de $10 \mathrm{t}$ de $\mathrm{MN}$ e $3 \mathrm{t}$ de MS.

0 produtor E possui uma área total de 64,70 ha, sendo 1,10 ha destinados a eucalipto $\mathrm{e}$ infraestrutura e o restante à produção de leite, assim distribuídos: a área de pastagem nativa é de 50,50 ha, com produção da MS de 151,50 t. A produção de capineira ocupa um espaço de 0,29 ha com produção de 11,60 t de MN e 2,90 t de MS.

A composição dos rebanhos e disponibilidade de pastagens e volumoso das propriedades estudadas podem ser observadas nas Tabelas 3,4 e 5, respectivamente.

Tabela 3 - Composição dos rebanhos e consumo de matéria seca (CMS) por ano, das cinco propriedades de agricultura familiar estudadas no município de Ponte Nova/MG (período de abril a junho de 2016)

\begin{tabular}{|c|c|c|c|c|c|c|c|c|c|c|}
\hline \multirow[b]{2}{*}{ Categoria animal } & \multicolumn{2}{|c|}{ Propriedade A } & \multicolumn{2}{|c|}{ Propriedade B } & \multicolumn{2}{|c|}{ Propriedade C } & \multicolumn{2}{|c|}{ Propriedade D } & \multicolumn{2}{|c|}{ Propriedade $\mathrm{E}$} \\
\hline & $\begin{array}{l}\text { Quant* } \\
\text { (n) }\end{array}$ & $\begin{array}{c}\text { CMS/ano } \\
\text { (t) }\end{array}$ & $\begin{array}{l}\text { Quant. } \\
\text { (n) }\end{array}$ & $\begin{array}{c}\text { CMS/ano } \\
\text { (t) }\end{array}$ & $\begin{array}{l}\text { Quant. } \\
\text { (n) }\end{array}$ & $\begin{array}{c}\text { CMS/ano } \\
(\mathrm{t})\end{array}$ & $\begin{array}{l}\text { Quant. } \\
\text { (n) }\end{array}$ & $\begin{array}{c}\text { CMS/ano } \\
\text { (t) }\end{array}$ & $\begin{array}{l}\text { Quant. } \\
\text { (n) }\end{array}$ & $\begin{array}{l}\text { CMS/ano } \\
\text { (t) }\end{array}$ \\
\hline $\begin{array}{l}\text { Vacas em } \\
\text { lactação }\end{array}$ & 15 & 73,91 & 6 & 29,57 & 8 & 39,42 & 1 & 4,93 & 15 & 73,91 \\
\hline Vacas secas & 8 & 26,28 & 3 & 9,86 & 4 & 13,14 & 5 & 16,43 & 5 & 16,43 \\
\hline $\begin{array}{l}\text { Bezerras de } 0 \mathrm{a} \\
12 \text { meses }\end{array}$ & 6 & 4,93 & 6 & 4,93 & 4 & 3,29 & 1 & 0,82 & 8 & 6,57 \\
\hline $\begin{array}{l}\text { Bezerras de } 12 \text { a } \\
24 \text { meses }\end{array}$ & 1 & 1,83 & 5 & 9,13 & 1 & 1,83 & 0 & 0,00 & 5 & 9,13 \\
\hline $\begin{array}{l}\text { Bezerras de } 24 \text { a } \\
36 \text { meses }\end{array}$ & 1 & 3,19 & 0 & 0,00 & 3 & 9,58 & 0 & 0,00 & 0 & 0,00 \\
\hline $\begin{array}{l}\text { Bezerros de } 0 \mathrm{a} \\
12 \text { meses }\end{array}$ & 7 & 5,75 & 3 & 2,46 & 3 & 2,46 & 1 & 0,82 & 4 & 3,29 \\
\hline Boi de carro & 2 & 6,57 & 0 & 0,00 & 0 & 0,00 & 0 & 0,00 & 0 & 0,00 \\
\hline Touros & 1 & 2,96 & 1 & 2,96 & 1 & 2,96 & 0 & 0,00 & 1 & 2,96 \\
\hline Cavalos & 2 & 6,57 & 2 & 6,57 & 1 & 3,29 & 0 & 0,00 & 3 & 9,86 \\
\hline Mulas & 3 & 7,67 & 0 & 0,00 & 0 & 0,00 & 0 & 0,00 & 0 & 0,00 \\
\hline TOTAL & 46 & 139,65 & 26 & 65,46 & 25 & 75,96 & 8 & 23,00 & 41 & 122,13 \\
\hline
\end{tabular}

Nota: ${ }^{*}$ Quant $=$ Quantidade. 
Tabela 4 - Produção de matéria seca das pastagens (em toneladas) por ano, das cinco propriedades de agricultura familiar estudadas no município de Ponte Nova/MG (período de abril a junho de 2016)

\begin{tabular}{cccccc}
\hline Propriedade & \multicolumn{5}{c}{$\begin{array}{c}\text { Tipo de } \\
\text { Pastagens }\end{array}$} \\
& 1 & 2 & 3 & 4 & Total \\
& 29,70 & 9,36 & 0,00 & 4,14 & 43,20 \\
\hline A & 0,00 & 0,00 & 16,20 & 0,00 & 16,20 \\
B & 0,00 & 0,00 & 12,00 & 18,03 & 30,03 \\
C & 0,00 & 0,00 & 9,60 & 9,03 & 18,63 \\
D & 0,00 & 0,00 & 0,00 & 151,50 & 151,50 \\
E &
\end{tabular}

Nota: 1-Braquiária (Brachiaria decumbens) em piquete; 2 - ILPF (Integração Lavoura-Pecuária-Floresta) com Braquiária (Brachiaria decumbens); 3 - Braquiária (Brachiaria brizantha ou decumbens); 4 - Meloso (Melinis minutiflora P. Beauv.)

Tabela 5 - Produção de matéria seca de alimentos volumosos (em toneladas) por ano, das cinco propriedades de agricultura familiar estudadas no município de Ponte Nova/MG (período de abril a junho de 2016)

\begin{tabular}{ccccc}
\hline Propriedade & \multicolumn{3}{c}{ Volumosos } & Total disponivel \\
& 1 & 2 & 3 & \\
\hline A & 7,60 & 17,70 & 42,00 & 67,30 \\
B & 2,30 & 3,00 & 14,00 & 19,30 \\
C & 2,00 & 7,50 & 0,00 & 9,50 \\
D & 0,00 & 3,00 & 0,00 & 3,00 \\
E & 2,90 & 0,00 & 0,00 & 2,90 \\
\hline
\end{tabular}

Nota: 1 - Capineira (Pennisetum purpureum); 2 -Cana-de-açúcar (Saccharum officinarum); 3 - Silagem de milho (Zea mays).

Dentre as propriedades estudadas, somente uma (20\%) possui alimentação volumosa suficiente, tendo uma sobra de MS de 32,27 t para o gado no decorrer de um ano; as demais (80\%) possuem quantidade de alimentos volumosos insuficiente, com saldos negativos de 29,15, 29,96, 36,43 e 1,37 $\mathrm{t}$, respectivamente para as propriedades A, B, C e D. A alimentação volumosa é fundamental para ajuste da capacidade de suporte das propriedades e tem menor impacto no custo operacional efetivo (COE) de produção, pois a mesma é produzida na propriedade. Apesar da alimentação representar
$56,7 \%$ do COE, a alimentação volumosa contribui com apenas $25,2 \%$ das despesas com alimentação, ou seja, 14,3\% do COE (Lopes et al., 2011; Santos e Lopes, 2012; Lopes e Santos 2013; Santos e Lopes, 2014; Lopes et al., 2015).

O sucesso na criação de gado leiteiro está ligado, dentre de outros fatores, à alimentação, pois esta é o componente do COE que mais impacta no custo de produção (Lopes et al., 2011; Santos e Lopes, 2012; Lopes e Santos 2013; Santos e Lopes, 2014; Lopes et al., 2015). Neste sentido, deve ser fornecida alimentação volumosa e concentrada com qualidade e em quantidade adequada, garantindo, assim, o bom desempenho dos animais e a lucratividade do sistema. Nas propriedades estudadas, os produtores precisam aumentar a produção de volumosos para atender ao rebanho já existente.

\section{Conclusão}

Dentre as propriedades estudadas, somente uma (E) possui alimentação volumosa suficiente para o gado; as demais ( $80 \%)$ possuem quantidade de alimentos volumosos insuficientes.

Existe uma grande necessidade de orientação por parte dos produtores de economia familiar sobre alternativas de produção de volumoso para a produção de leite.

\section{Agradecimentos}

Os autores agradecem à EMATER - MG por ter possibilitado a realização desta pesquisa, e ao CNPq pela concessão de bolsa de produtividade ao segundo autor.

\section{Referências}

Campos AT, Ferreira AM. Composição do rebanho e sua importância no manejo. In: Instrução técnica para o produtor de leite. EMBRAPA: 2006 [acesso 6 jan. 2017]. Disponível em: https://tinyurl.com/y9m77sac.

Cruz JC, Pereira Filho IA. Cultivares de milho para silagem. In: Cruz JC, Pereira Filho IA, Rodrigues JAS, Ferreira JJ. 
Produção e utilização de silagem de milho e sorgo. Sete Lagoas: Embrapa Milho e Sorgo; 2001. p.11-37.

Daniel JLP, Zopollatto M, Nussio LG. A escolha do volumoso suplementar na dieta de ruminantes. R Bras Zootec. 2011;40(supl. especial):261-9.

IBGE - Instituto Brasileiro de Geografia e Estatística. 2016 [acesso 12 dez. 2016]. Disponível em: http://ibge.gov.br.

Ferrazza RA, Lopes MA, Moraes F, Bruhn FRP. Índices de desempenho zootécnico e econômico de sistemas de produção de leite com diferentes níveis tecnológicos. Semin: Cien Agrar. 2015;36(1):485-96.

Ferreira JJ. Características qualitativas e produtivas da planta de milho e sorgo para silagem. In: Cruz JC, Pereira Filho IA, Rodrigues JAS, Ferreira JJ. Produção e utilização de silagem de milho e sorgo. Sete Lagoas: Embrapa Milho e Sorgo; 2001. p.383-404.

França CG, Del Grossi ME, Marques VPMA. O censo agropecuário 2006 e a agricultura familiar no Brasil. Brasília: MDA; 2009. 95 p.

França GE, Coelho AM. Adubação do milho para silagem. In: Cruz JC, Pereira Filho IA, Rodrigues JAS, Ferreira JJ. Produção e utilização de silagem de milho e sorgo. Sete Lagoas: Embrapa Milho e Sorgo; 2001. p.53-83.

Lopes MA, Lima ALR, Carvalho FM, Reis RP, Santos IC, Saraiva FH. Controle gerencial e estudo da rentabilidade de sistemas de produção de leite na região de Lavras (MG). Cienc Agrotec. 2004;28(4)883-92.

Lopes MA, Moraes F, Carvalho FM, Peres ACC, Bruhn FRP, Reis EMB. The effect of technological levels on profits of milk production systems participating in the "full bucket” program: a multicase study. Semin: Cien Agrar. 2015;36(4):2909-22.

Lopes MA, Reis EMB. Formulário de diagnóstico da propriedade leiteira: pastagem. Lavras: Editora da UFLA; $2016.8 \mathrm{p}$

Lopes MA, Santos G. Análise de rentabilidade de fazendas leiteiras em regime de semiconfinamento com alta produção diária. Informações Econômicas. 2013;43(3):65-74.
Lopes MA, Santos G, Carvalho FM. Indicadores econômicos da atividade leiteira em regime de semiconfinamento com alta produção diária. B Industr Anim. 2011;68(2):113-23.

Lopes MA, Santos G, Franco Neto A, Lopes LMF, Demeu FA, Resende BL. Resultados econômicos de um sistema de produção de leite no município de Itutinga - MG. B Industr Anim. 2012;69(1):23-31.

Magalhães ALR, Campos JMS, Valadares Filho SC, Torres RA, Mendes Neto J, Assis AJ. Cana-de-açúcar em substituição à silagem de milho em dietas para vacas em lactação: Desempenho e Viabilidade econômica. R Bras Zootec. 2004;33(5):1292-302.

Magalhães JA, Carneiro MSS, Bezerra APA, Morais Neto LB, Costa MRGF, Mochel Filho WJE. Considerações sobre a produção de leite a pasto. Rev Electrón Vet. 2007;8(9):1-9.

Mc-Collum T. Alimentação suplementar de vacas e bovinos em crescimento a pasto. In: Anais do IX Novos Enfoques na Produção e Reprodução de Bovinos; 2005; Uberlândia. Uberlândia: Consultoria Agropecuária Júnior; 2005. p. 157-62.

Moreira HA. Suplementação de concentrados para vacas leiteiras. 2 ed. Brasília: EMBRATER; 1983.14 p.

Nussio LG, Lima LG, Mattos WRS. Planejamento da produção de alimentos para o inverno. In: Anais do $10^{\circ}$ Simpósio sobre Produção Animal; 1998; Piracicaba. Piracicaba: Fundação de Estudos Agrários Luiz de Queiroz; 1998.

Oliveira IS, Cabral LS, Zervoudakis JT, Abreu JG, Rodrigues RC, Morenz MJF. Consumo, digestibilidade e desempenho de vacas leiteiras submetidas a dietas baseadas em volumosos tropicais no Centro Oeste do Brasil. Livestock Res Rural Dev. 2011;23(11):224.

Reis RB, Antunes RC. Alimentação de vacas de alta produção. In: II Simpósio Mineiro de Nutrição de Gado De Leite; 1999; Belo Horizonte. Belo Horizonte: UFMG; 1999. p. 99-115.

Santos G, Lopes MA. Indicadores econômicos de sistemas de produção de leite em confinamento total com alto volume de produção diária. Cienc Anim Bras. 2014;15(3):239-48. 
Santos G, Lopes MA. Indicadores de rentabilidade do centro de custo produção de leite em sistemas intensivos de produção. B Industr Anim. 2012;69(1):1-11.

Silva JJ, Carvalho DMG, Gomes RAB, Rodrigues ABC. Produção de leite de animais criados em pastos no Brasil. Vet Zootec. 2010;17(1):26-36.

Teixeira Jr FEP, Ruas JRM, Lopes MA, Costa MD, Pires DAA, Rocha Jr VR. Effect of different alternative roughages on the profitability of milk production systems with F1 Holstein x Zebu cows. Rev Ceres. 2016;63(6):807-15.

Viana MCM, Magalhães LL, Queiroz DS, Ofugi C, Melido RCN, Gomes RJ, Mascarenhas MHT. Experiências com o Sistema Integração Lavoura-Pecuária-Floresta em Minas Gerais. Informe Agropecuário. 2010;31(257):98-111.

Zoccal R, Souza AD, Gomes AT. Produção de leite na agricultura familiar. In: Boletim de Pesquisa e Desenvolvimento 17. Juiz de Fora: Embrapa Gado de Leite; 2005. 20 p.

Recebido em: 15/03/2017

Received in: 03/15/2017

Aprovado em: 04/07/2017

Approved in: 07/04/2017 